\title{
Enhancing hydrogen production from steam electrolysis in molten hydroxides via selection of non-precious metal electrodes
}

a School of Mechanical, Aerospace and Automotive Engineering, Faculty of Engineering,

7 Environmental and Computing, Coventry University, Coventry CVI 2JH, UK

$8{ }^{b}$ Department of Chemical and Environmental Engineering, University of Nottingham, University

9 Park, Nottingham NG7 2RD, UK

$10{ }^{c}$ Department of Biochemistry, University of Agriculture, Faisalabad 38000, Pakistan

$11{ }^{d}$ School of Chemical and Materials Engineering, National University of Sciences and Technology,

12 Islamabad 44000, Pakistan

$13{ }^{e}$ Department of Chemical and Environmental Engineering, Faculty of Science and Engineering,

14 University of Nottingham Ningbo China, University Park, Ningbo 315100, China

16 *Corresponding authors:

17 E-mail address: Farooq.Sher@ coventry.ac.uk (F.Sher), George.Chen@ nottingham.ac.uk (G.Chen)

\section{Abstract}

20 There are still gaps in the field of reference electrode that is needed to assist electrolysis in high

21 temperature electrolytes (e.g. molten hydroxides) for $\mathrm{H}_{2}$ gas production. This research aims to fill

22 the gaps by preparing the $\mathrm{Ni} / \mathrm{Ni}(\mathrm{OH})_{2}$ reference electrode and, more importantly, testing its

23 effectiveness against important performance factors, including ion conducting membrane (e.g.

24 mullite tubes), internal electrolyte composition, working temperature and electrochemical control

25 (e.g. potential scan rate). Then, this reference electrode was used to assist the study of the 26 electrocatalytic activity of a range of cheaper working electrode materials, including stainless steel

27 (St.st), Ni, Mo and Ag, in comparison with Pt, by means of chronoamperometry and voltammetry.

28 The effect of introducing steam into the electrolyte (eutectic mixture of $\mathrm{NaOH}$ and $\mathrm{KOH}$ ) on the 29 electrocatalytic activity of each of these working electrodes was also studied. It was observed that 
30 the potential of hydrogen evolution on different working electrodes followed an order of Pt $>\mathrm{Ni}$

$31>$ St.st $>$ Ag > Mo (positive to negative). The performance of each working electrode was

32 confirmed through chronoamperometry for hydrogen evolution at a constant potential of $-0.7 \mathrm{~V}$. It

33 was also found in cyclic voltammetry and confirmed by chronoamperometry that the introduction

34 of steam was apparent in increasing the current density at the cathodic limit for hydrogen evolution.

35 It is hoped that this study will help develop non-precious metal electrodes for the production of

36 the hydrogen fuel. In future, there will be a potential in the threshold concentration of steam for

$37 \mathrm{H}_{2}$ gas production.

39 Keywords: Renewable energy, Hydrogen production; Electrocatalytic activity; Water splitting;

40 Reference electrode, Fuel cells and Chronoamperometry.

\section{Introduction}

43 An important pollution free fuel that can meet future needs and can also lessen the problems

44 instigated by the consumption of conventional fuels is hydrogen $\left(\mathrm{H}_{2}\right)$. As a highly efficient fuel,

$45 \mathrm{H}_{2}$ can be used for power generation, transportation and heating, and has the potential to substitute,

46 at least partly, existing fuels. It is well documented and highlighted more recently that the

47 commonly used process for $\mathrm{H}_{2}$ production from water, as a renewable and clean source [1], is

48 electrolysis which splits water into its core ingredients; $\mathrm{H}_{2}$ and oxygen $\left(\mathrm{O}_{2}\right)[2,3]$. Splitting of

49 water, or more accurately steam in high temperature molten hydroxides, by means of electrolysis

50 has great importance and advantages. 
52 The main advantage is that in the electrolysis, heat is used as a source of energy and heat is cheaper

53 than electricity in terms of sources and conversion (production). The conductivity of a hydroxide

54 electrolyte at high temperatures is very good and increases with increasing temperature. The

55 hydroxide electrolyte at high temperatures is specific to reduce the loss of energy due to the

56 overpotential of an electrode through acceleration of the reaction kinetics [4]. All these contribute

57 to increasing the net energy efficiency of the process. Molten hydroxides could themselves play

58 the role of a catalyst during the reaction and thus in this technology, there is no need for precious

59 metals as a catalyst [5]. On increasing the temperature, the decomposition voltage of a compound

60 is usually reduced, and this phenomenon is well observed in the case of water electrolysis. In the

61 case of a thermally insulated electrolysis cell, energy consumption is constantly minimised [6].

62 This can be considered for long term electrolysis. Another advantage of electrolysis at high

63 temperatures is that the current flowing continuously through the molten electrolyte contributes to

64 additional internal heating that is needed to compensate any heat loss that is inevitable, even in a

65 thermally well-insulated cell.

66

67 Suitable ion conducting membrane materials are required for the better fabrication of a reference

68 electrode. Therefore, the selection of good ion conducting materials in this field is very important

69 especially in the case of high temperature electrolytes. The redox couple, $\mathrm{Ag} / \mathrm{AgCl}$, is commonly

70 used in reference electrodes coupled with different ion conducting membrane materials, such as

71 quartz, Pyrex, porcelain, and mullite $[7,8]$. The $\mathrm{Ag} / \mathrm{AgCl}$ couple contained in silica tube covered

72 with graphite, or enclosed in alumina membrane [9] have also been stated as choices for high

73 temperature molten salts. Selection of membrane materials is important for the fabrication of an 
74 electrode in molten hydroxides. Thus, those ionic membranes with good chemical stability,

75 reusability and reproducibility are important [10-12].

77 Several studies have previously investigated the use of different working electrodes such as nickel

78 (Ni) [13, 14], platinum (Pt) [15], sliver (Ag) [16], molybdenum (Mo) [17] or stainless steel (St.st)

79 [18]. These working electrodes have the ability to conduct an adequate catalytic activity for

80 splitting water in hydroxide electrolyte; resulting in the enhancement of reaction kinetics and a

81 subsequent upturn in the production of $\mathrm{H}_{2}$ gas. These metals were either investigated in a molten

82 hydroxide or in an aqueous solution of hydroxide at low temperatures. These studies under

83 different operating conditions used hydroxide and a different type of reference electrode to control

84 the working electrode. For instance, Miles et al. [13] studied the electrochemistry of molten $\mathrm{NaOH}-$

$85 \mathrm{KOH}$ salt at $280{ }^{\circ} \mathrm{C}$ using platinum, nickel and silver as working electrodes against the reference

86 electrode of $\mathrm{Ag}^{+} / \mathrm{Ag}$.

88 The study of Ge et al. [15] involved cyclic voltammetry on a Pt or Ni wire, or a NiO pellet as the

89 working electrode in fused $\mathrm{NaOH}$ at $550{ }^{\circ} \mathrm{C}$. A $\mathrm{Ni}$ rod was selected as the pseudo reference

90 electrode for the analysis of $\mathrm{NiO}$ reduction mechanism into the melt. Zabinski et al. [19] employed

91 a Co-Mo-C alloy to augment the cathodic potential for electrolytic evolution of $\mathrm{H}_{2}$ in a solution of

$928 \mathrm{M} \mathrm{NaOH}$ at $90{ }^{\circ} \mathrm{C}$. This was also carried out to inhibit the dissolution of Mo during open circuit

93 dipping in the solution. Another investigation [20] coated the St.st electrode with a Ni-Mo-Fe film

94 to enhance the catalytic activity for $\mathrm{H}_{2}$ evolution in the dilute basic solution. When $\mathrm{Ni}$, Co and

95 NiCo were used as coatings to support a carbon felt electrode, this also resulted in enhanced

96 catalytic activity for the $\mathrm{H}_{2}$ evolution reaction (HER) [21]. 
98 This study is carried out to fabricate and test the $\mathrm{Ni} / \mathrm{Ni}(\mathrm{OH})_{2}$ reference electrode with an ion

99 conducting mullite membrane. The reasons behind choosing $\mathrm{Ni}$ for the reference electrode

100 fabrication were its range of chemical, physical, electrocatalytic, structural and corrosion resistant

101 properties $[22,23]$. Also, the electrocatalytic activity of a range of cheap working electrodes was

102 comprehensively studied against this novel reference electrode. Then, the potentials of these cheap

103 working electrodes for hydrogen gas production via splitting water were assessed in the presence

104 of the eutectic mixture of $\mathrm{NaOH}-\mathrm{KOH}(49: 51, \mathrm{~mol} \%)$ at $300{ }^{\circ} \mathrm{C}$. The effect of steam at the

105 electrocatalytic activity of these working electrodes has also been studied. Chronoamperometry

106 and cyclic voltammetry were used to investigate the electrocatalytic activity of the working

107 electrodes in this study.

108

1092 Materials and methods

$110 \quad 2.1$ The $\mathrm{Ni} / \mathrm{Ni}(\mathbf{O H})_{2}$ reference electrode

$111 \mathrm{The} \mathrm{Ni} / \mathrm{Ni}(\mathrm{OH})_{2}$ reference electrode was fabricated with a mullite tube (Multi-Lab Ltd) as the ionic

112 membrane. The mullite tube consisted of $\mathrm{Al}_{2} \mathrm{O}_{3}$ and $\mathrm{SiO}_{2}(36: 62$, mol\%) with the diameter, length

113 and thickness being $5 \mathrm{~mm}, 500 \mathrm{~mm}$ and $1 \mathrm{~mm}$, respectively. The tube had $0.02 \mathrm{vol} \%$ of water

114 absorption aptitude with $2.7 \mathrm{~g} \mathrm{~cm}^{-3}$ of bulk density. The internal electrolyte was prepared by mixing

$1151.0 \mathrm{~mol} \% \mathrm{Ni}(\mathrm{OH})_{2}$ (Arcos Organics) with the eutectic mixture of $\mathrm{NaOH}$ and $\mathrm{KOH}(49: 51, \mathrm{~mol} \%)$.

116 Then this mixture was implanted into the conducting ionic mullite tube. This synthesised mixture

117 was used internally as an electrolyte. The solubility of the $\mathrm{Ni}(\mathrm{OH})_{2}$ in the internal electrolyte of a

118 reference electrode is of great importance. It was described by researchers in past that the 
119 dissolution of the $\mathrm{Ni}(\mathrm{OH})_{2}$ in basic solution was not significant at room temperature, this trend was

120 observed to be opposite in case of acidic solution [24].

121

122 On the other hand, $\mathrm{Ni}(\mathrm{OH})_{2}$ has a solubility product of $6.5 \times 10^{-18}$, and this value was unaffected 123 when noticed from the reaction of $\mathrm{Ni}(\mathrm{OH})_{2}$ with either acid or base. Therefore, a minute amount 124 of $1.0 \mathrm{~mol} \%$ of $\mathrm{Ni}(\mathrm{OH})_{2}$ was applied in the internal electrolyte. This composition was previously 125 reported for a high $\mathrm{H}_{2}$ evolution rate [25]. The hydroxide mixture (1.16 g) was placed inside the 126 mullite tube which was positioned inside the retort, but it was quickly filled with the mixture of 127 the salts of hydroxides when the tube outside the crucible, to avoid any absorption of moisture 128 contents from the open air. The internal and external composition of the eutectic hydroxides should 129 be the same. The temperature was then raised up to $300{ }^{\circ} \mathrm{C}$ to thoroughly melt the mixtures of 130 hydroxide salts in the mullite tube membrane. The tube was filled up to the length of $12 \mathrm{~cm}$. After 131 that a Ni wire with $0.5 \mathrm{~mm}$ diameter and $99.98 \%$ pure temper annealed was introduced inside the 132 tube.

134 The Ni wire was enclosed inside the mullite tube the left this for overnight to accomplish the 135 melting of the salts mixture at $300{ }^{\circ} \mathrm{C}$. Next to this, the furnace was cooled to the required 136 temperature to solidify the molten melts mixture in the tube and sealed it. Alumina crucible with $137280 \mathrm{~mL}$ volume and $120 \mathrm{~mm}$ height (Almath Crucibles Ltd) was used for the performance 138 evaluation of the Ni reference electrode. Argon atmosphere was applied for these test by using an 139 electrochemical analyser of Iviumn Stat multi-channel. For all these experiments $250 \mathrm{~g}$ of the 140 molten hydroxides was left in the presence of $40 \mathrm{~cm}^{3} \mathrm{~min}^{-1}$ of argon gas for $24 \mathrm{~h}$ and $300{ }^{\circ} \mathrm{C}$ 141 temperature before use. The experimental setup for the designed electrodes is presented in Fig. 1 


\section{$143 \quad 2.2$ Specifications of working electrodes}

144 The counter electrode used in this study was prepared of stainless steel rod of 304 Grade, along 145 with the diameter of $5 \mathrm{~mm}$ (Unicorn Metals). Five different types of working electrodes were used 146 including Ni, Pt, Ag, Mo, and St.st. The dimensions and properties of these working electrodes are 147 as follows. The $99.98 \%$ pure Temper Annealed Ni working electrode was used with a $0.5 \mathrm{~mm}$ 148 diameter. The Pt working electrode was 99.95\% pure Temper Annealed this was also about 0.5 149 mm diameter. The third used working electrode was Ag with 99.99\% pure Temper Annealed and $1501.0 \mathrm{~mm}$ in diameter. The Mo working electrode was of $1.0 \mathrm{~mm}$ diameter and $99.95 \%$ pure Temper 151 Annealed. The last working electrode was St.st with $0.25 \mathrm{~mm}$ diameter and $99.99 \%$ pure Temper 152 Annealed. All these working electrodes were obtained from Advent Research Material.

154 The performance of the working electrodes was carried out in a cylindrical alumina crucible using 155 the same protocol as conducted for the reference electrode. Though, it was not easy in practice to 156 attain the exact requisite temperature because the electrolyte temperature is dependant on furnace

157 temperature. So the temperature variation can be controlled by the furnace temperature. The 158 furnace controller of temperature had an accuracy of $\pm 1^{\circ} \mathrm{C}$. In addition to the furnace temperature 159 electrolyte temperature was also affected by some other factors. Including the furnace insulation 160 effectiveness and the ambient temperature.

\section{$162 \quad 2.3 \quad$ Electrochemical investigation}

163 The electrochemical methods used in this investigation were cyclic voltammetry and 164 chronoamperometry. These techniques were used to study the behaviour of the working electrodes 
165 in the molten salts at variable working conditions [26]. The measurements were made between one

166 of the working electrodes (e.g. Ni, Pt, Ag, Mo, St.st) and the designed reference electrode of Ni.

167 The depth of immersion for the working electrodes was $\sim 14 \mathrm{~mm}$ inside the electrolyte. Cyclic

168 voltammetry (CV) measurements were noted from negative circuit potential to a positive one.

169 These type of analyses are very important that have already been used in different studies [27, 28].

170 CV investigations were also conducted at different temperatures and in the presence of steam

171 inside molten salts. Introduction of the steam at $7.28 \mathrm{~cm}^{3} \mathrm{~min}^{-1}$ flow rate was fixed, mixing with

172 argon gas that itself flows at $40 \mathrm{~cm}^{3} \mathrm{~min}^{-1}$.

173

174 The mixture of argon and steam was effervesced inside the molten salts. CV plots are plotted as

175 current density versus potential. Table 1 shows the working electrodes used in this study, their

176 diameters and calculated surface area respectively. The information regarding the different

177 operating temperatures included as supplementary material. The surface area of the working

178 electrodes can be calculated using Eq. (1).

179

$180 \quad \mathrm{~A}=\pi \times \mathrm{D} \times \mathrm{h}+\frac{1}{4} \times \pi \times \mathrm{D}^{2}$

182 where A: the surface area of the immersion part inside the melt $\left(\mathrm{cm}^{2}\right), \pi$ : mathematical constant

183 (3.141), D: diameter of the working electrode $(\mathrm{cm})$, and h: the immersion depth of the wire inside 184 the electrolyte $(\mathrm{cm})$.

185

1863 Results and discussion 
187 In this section cyclic voltammetry scans were performed for different working electrodes (e.g. Ni,

$188 \mathrm{Pt}, \mathrm{Ag}, \mathrm{Mo}$ and St.st) in eutectic molten hydroxide as explored below:

\subsection{Cyclic voltammetry investigation of working electrodes}

\section{$191 \quad 3.1 .1 \quad$ Ni working electrode}

192 To determine the functioning of different metal electrodes against the designed reference electrode

193 cyclic voltammetry analyses were performed $[29,30]$. For this, in the first run blank, Ni wire as a

194 working electrode is used at a temperature of $300{ }^{\circ} \mathrm{C}$ and $100 \mathrm{mVs}^{-1}$ scan rate using the prepared

195 nickel reference electrode in molten hydroxide. Fig. 2(a) displays the obtained cyclic voltammetry

196 full scan. Fig. 2(b) shows cyclic voltammetry scanned from -0.8 V to -0.1 V vs reference electrode.

197 The latter only focuses on the reduction limit.

199 The number of redox peaks can be easily noted as shown in Fig. 2(a). The C2 peak is the cathodic 200 current credited to the oxide's film reduction [31], made on Ni wire surface, while the A2 peak is 201 anodic current attributed to its oxidation. In addition, the reduction potential started at $-0.465 \mathrm{~V}$ 202 likely corresponds to the evolution of $\mathrm{H}_{2}$ gas $[15,32]$ and the resultant chemical process is shown 203 in Fig. 2(a) and expressed as reaction (2). The peak A1 is assigned to the generation of oxygen gas 204 as seen in Fig. 2(a) and represented as reaction (3).

205

$2062 \mathrm{H}_{2} \mathrm{O}+2 \mathrm{e}^{-} \rightarrow \mathrm{H}_{2}(\mathrm{~g})+2 \mathrm{OH}^{-}$

$$
2 \mathrm{OH}^{-} \rightarrow \frac{1}{2} \mathrm{O}_{2}(\mathrm{~g})+\mathrm{H}_{2} \mathrm{O}+2 \mathrm{e}^{-}
$$


208 The peak C2 in Fig. 2(a) has a potential of $-0.37 \mathrm{~V}$ which is scarcely noticeable compared to peak 209 A2 in the first potential cycle (Fig. 2(a)). The redox reactions occurred at the Ni electrode surface 210 in the eutectic molten hydroxides can be credited to this phenomenon [15]. The peak A2 denotes

211 the oxidation of $\mathrm{Ni}$ wire [33], which may cause the accumulation of oxide layer on the nickel

212 surface. Consequently, the peak C2 observed because of the reduction of this oxide layer.

213 Furthermore, on limiting the applied voltage between $-0.8 \mathrm{~V}$ and $-0.1 \mathrm{~V}$, the $\mathrm{C} 2$ peak vanishes as 214 in Fig. 2(b) due to the lack of oxidation of the nickel wire.

216 The disappearance of the reduction peak C2 as shown in Fig. 2(a), reveals that no distinctive 217 reduction peak in this potential scan was confirmed when the scan was limited as shown in Fig. 218 2(b). For the understanding of this reaction, the potential of $\mathrm{H}_{2} \mathrm{O}$ and $\mathrm{NiO}$ decomposition at 300 $219{ }^{\circ} \mathrm{C}$ temperature was measured by the help of HSC 6.0 software. The decomposition reactions are 220 (4 and 5). It reveals from these findings that the two decomposition potentials are quite close, 221 showing that those reactions may occur at the same time during the cathodic sweep. This finding 222 agrees with [15] who stated that the decomposition potentials of water and nickel oxide at $550{ }^{\circ} \mathrm{C}$ 223 were very close.

$225 \quad \mathrm{H}_{2} \mathrm{O} \rightarrow \mathrm{H}_{2}(\mathrm{~g})+\frac{1}{2} \mathrm{O}_{2}(\mathrm{~g}) \quad(\mathrm{E}=-1.013 \mathrm{~V})$

$226 \quad 2 \mathrm{NiO} \rightarrow 2 \mathrm{Ni}+\mathrm{O}_{2}(\mathrm{~g}) \quad(\mathrm{E}=-0.965 \mathrm{~V})$

228 Fig. 2(c) shows the CV plot of Ni working and reference electrode with and without the presence 229 of steam at a temperature of $300{ }^{\circ} \mathrm{C}$ and $100 \mathrm{mV} \mathrm{s}^{-1}$ scan rate. No substantial change in the anodic 230 peak A2 (oxidation of $\mathrm{Ni}$ ) is witnessed with the introduction of steam inside the molten melt as 
231 presented in Fig. 2(c). At cathodic limit, an increase in the current density is noted that increases

232 from $-1.6 \mathrm{~A} \mathrm{~cm}^{-2}$ to $-2.09 \mathrm{~A} \mathrm{~cm}^{-2}$ with the existence of steam. In order to exhibit the effect of the

233 presence of steam in increasing the evolution of $\mathrm{H}_{2}$ gas, the potential scan is limited between -0.8

234 and $-0.3 \mathrm{~V}$ as shown in Fig. 2(d). It is obvious from the figure that the reduction potential for the

235 evolution of $\mathrm{H}_{2}$ gas is the same with and without steam. However, the effect of steam can be

236 recognised by enhancing the current density limit for the evolution of hydrogen gas. This increase

237 represents the amount of steam that exists with molten melt and contributed to an increase in the 238 yield of the hydrogen gas.

\subsubsection{Pt working electrode}

241 In electrochemical studies Pt has great importance because of its good stable characteristics, 242 therefore here Pt working electrode in molten hydroxide is used to achieve reliable CV scans 243 against the designed Ni reference electrode [15]. Fig. 3(a) shows the CV plot of the Pt working 244 electrode in the eutectic molten melt at the same conditions of temperature and scan rate like the 245 previous Ni working electrode. It can be observed from Fig. 3(a) that the anodic limit A1 is 246 observed because of the oxidation of the eutectic molten hydroxides [34] as in reaction (3). While 247 the water reduction, made at the anode, derives the cathodic limit C1 [34] as in reaction (6).

$\mathrm{H}_{2} \mathrm{O}+\mathrm{e}^{-} \rightarrow \frac{1}{2} \mathrm{H}_{2}(\mathrm{~g})+\mathrm{OH}^{-}$

251 Therefore the corresponding potential for hydrogen gas evolution at $\mathrm{C} 2$ is $-0.44 \mathrm{~V}$. To focus the 252 scan on the cathodic limit the applied potential is limitised between -0.8 and $-0.3 \mathrm{~V}$ as shown in 253 Fig. 3(b). As because of this potential limitation, the scan is still stable but the reduction potential 254 shifts negatively to a value of about $0.04 \mathrm{~V}$ smaller than the full scan. Furthermore, the potential 
255 scan rate varies for the purpose of testation of the platinum working electrode in the settled 256 conditions of temperature and molten hydroxide.

258 Furthermore, to the above factors, it is imperative as well to study the effect of steam in the eutectic

259 fused salts with Pt wire working electrode. The reason for investigating this factor is to understand

260 its effect on the behaviour of the platinum working electrode. The cyclic voltammogram scan can

261 translate this change to the behaviour of the electrode. Fig. 3(c) shows the CV scan of platinum as

262 a working electrode with and without the presence of steam. The cyclic voltammetry scan

263 compares the influence of the presences of steam inside the eutectic molten hydroxide with the

264 cyclic voltammetry scan without steam as shown in Fig. 3(c) at a temperature of $300{ }^{\circ} \mathrm{C}$ and a scan

265 rate of $100 \mathrm{mV} \mathrm{s}^{-1}$. The presence of steam inside the eutectic molten hydroxide directly affects the

266 obtained cyclic voltammetry scan by increasing the flow of current density at the cathodic limit

267 from $1.16 \mathrm{~mA} \mathrm{~cm}^{-2}$ at $\mathrm{C} 1$ to $1.82 \mathrm{~mA} \mathrm{~cm}^{-2}$ at $\mathrm{C} 1$ '. This attributed to the increase steam bubbles

268 around the cathode which upon electrolysis generate more hydrogen gas this is also well mentioned

269 in literature [35].

270

271 For more clarification, the cyclic voltammetry scans are limited between -0.8 to $-0.3 \mathrm{~V}$ with and

272 without the presence of steam in the eutectic molten hydroxide, as shown in Fig. 3(d). There is no

273 change in the cyclic voltammetry scan due to this limitation. The presence of steam merely

274 influences the scan by increasing the current density limit of $\mathrm{C} 1$ to $\mathrm{C} 1$ ' which represents the

275 reaction of the evolution of hydrogen gas. Even though the platinum electrode is a stable metal in

276 a eutectic molten hydroxide at high temperatures; it still has limited use in the industry because it

277 is classified as a precious metal [36]. 
$279 \quad$ 3.1.3 Ag working electrode

280 The blank CV scan is also recorded for a silver working electrode in the studied molten melts, at 281 a $300{ }^{\circ} \mathrm{C}$ temperature and $100 \mathrm{mV} \mathrm{s}^{-1}$ scan rate as shown in Fig. 4(a). Literature is scarce regarding 282 the exact nature of the silver wire reaction in the hydroxide. For example, the research directed by 283 Miles et al. [13] reported that the reaction of the silver wire in the molten hydroxides may involve $284 \mathrm{Ag}^{+} \rightarrow \mathrm{Ag}, \quad \mathrm{AgO} \rightarrow \mathrm{Ag}+\mathrm{O}_{2}$ or some other silver electrode reaction. In this experiment of $\mathrm{Ag}$ 285 working electrode with $\mathrm{Ni} / \mathrm{Ni}(\mathrm{OH})_{2}$ reference similar findings have been noted as of [13].

287 A couple of redox peaks observed in the CV scan of Ag electrolysis as displayed in Fig. 4(a). 288 Therefore, the anodic peak A2 may be ascribed to the oxidation whereas the cathodic peak C2 is 289 because of the reduction reaction. These peaks noted because of the oxide layer made on the 290 surface of the silver wire. Moreover, the cathodically augmented current of C1 at $-0.52 \mathrm{~V}$ 291 corresponds to the evolution of $\mathrm{H}_{2}$ gas, these results are in connection with [32]. Equivalent to this, 292 cathodic chemical reaction shown in equation (2). Reaction (3) represents the generation of oxygen 293 gas as appears in peak A1 of Fig. 4(a). Formation of steam/ or water molecule noted from these 294 mentioned equations.

296 Subsequently, the cyclic voltammetry scan is limited between -0.8 and -0.3V as shown in Fig. 4(b) 297 to emphasise on the cathodic limit of the evolution of hydrogen gas. It can be observed from Fig. 298 4(b) that during this limited scanning, there is no considerable change in the starting point of the 299 potential at the cathodic limit. Moreover, it can be noted that the current density at C1' decreased. 300 The current density at the cathodic peak $\mathrm{C} 1$ as shown in Fig. 4(a) is roughly about $-0.61 \mathrm{~A} \mathrm{~cm}^{-2}$, 301 decreasing to approximately $-0.18 \mathrm{~A} \mathrm{~cm}^{-2}$ at $\mathrm{C}^{\prime}$ Fig. 4(b) during the limited scan potential. The 
302 disappearance of the oxidation peak A2 and the reduction peak C2 during the potential scan

303 limitisation is because of the scan starts at potential more negative than the oxidation potential of

304 silver wire. In this case, the decrease in the current density of C1' should be proportional to the

305 silver oxide's reduction to silver. Therefore, it should be mentioned that the silver oxide does not

306 completely reduce at $\mathrm{C} 2$, but its reduction is completed at $\mathrm{C} 1$ simultaneously with the evolution

307 of hydrogen reaction as seen in Fig. 4(a). This conclusion is based on a noticeable increase in the

308 current density, which otherwise decreases when the potential scan is limited.

310 To understand the influence of steam in molten salts on the hydrogen gas evolution with $\mathrm{Ag}$ 311 working electrode experiments performed at $300{ }^{\circ} \mathrm{C}$ and $100 \mathrm{mV} \mathrm{s}^{-1}$ Fig. 4(d). These experiments

312 were performed on the cathodic limit. The presence of steam with molten melt did not affect the 313 reduction potential of the evolution of hydrogen gas reaction as shown in Fig. 4(d). Thus, the same

314 scan was produced without steam as well. This stable behaviour of the scan can be attributed to 315 how the silver working electrode works in the molten melts against the Ni working electrode. It 316 can also describe in this way that Ag working electrode remains stable and did not show any active 317 response against the steam. Ag stability is somehow opposite to electrocatalytic activity. 318 Moreover, this stable behaviour is associated with the nobel metal properties of the Ag [37, 38].

319 Nobel metals ( $\mathrm{Ag}, \mathrm{Cu}$ and $\mathrm{Au}$ ) are least reactive against acids that is why use frequently for 320 ornamental purposes due to lower reactivity. So this stable behviour of the Ag metal in steam is 321 directly linked with its noble or inert metal charcteristics, further steam is amphoteric (acts as both 322 acid and base) in nature.

\section{$324 \quad 3.1 .4 \quad$ Mo working electrode}


325 Molybdenum is one of the transition metals. It has a good electrocatalytic capacity for enhancing

326 the activity of other metals such as nickel [20]. Due to the electroactivity of the molybdenum, it

327 was investigated as a working electrode in this study. Fig. 5(a) and b show the CV of the

328 molybdenum working electrode vs Ni reference electrode at same conditions of temperature and

329 scan rate. It can be observed from Fig. 5(a), that the electrochemical stability window is between

330 A and A' (approximately $0.33 \mathrm{~V}$ ). The increase in the cathode current density corresponds to the

331 evolution of $\mathrm{H}_{2}$, similar current density increase is detected at $\mathrm{C} 1$ and $-0.8 \mathrm{~V}$ [32]. Equivalent to

332 this, a chemical equation is shown in reaction (2). While anodically an increase in the current at

333 A1 corresponds to the oxygen gas evolution as can be observed in reaction (3).

335 The subsequent cyclic voltammetry scan is limited between -0.8 and $-0.2 \mathrm{~V}$ as shown in Fig. 5(b)

336 to focus on the evolution of the hydrogen gas reaction. Therefore, no change in the reduction peak

337 can be noticed if the scan range is limited to the potential located after the potential of the oxidation

338 peak A' reaction takes place. The effect of the presences of steam inside the molten salts on the

339 molybdenum working electrode electrocatalytic behaviour for increasing the hydrogen and oxygen

340 gas evolution is also considered. Fig. 5(c) and Fig. 5(d) show the CV scans of the molybdenum

341 working electrode against the $\mathrm{Ni} / \mathrm{Ni}(\mathrm{OH})_{2}$ reference electrode with and without steam with eutectic

342 melt.

343

344 It is obvious from Fig. 5(c) that the effect of the presence of steam is apparent in increasing the

345 current density of the evolution of hydrogen gas at the cathodic limit $\mathrm{C} 1$ ', and the simultaneous

346 evolution of oxygen gas at the anodic limit A1'. At the cathodic limit, the current enhances from -

$3470.12 \mathrm{~A} \mathrm{~cm}^{-2}$ without the presence of steam at point $\mathrm{C} 1$ to $-0.49 \mathrm{~A} \mathrm{~cm}^{-2}$ with the presence of steam 
348 at point $\mathrm{Cl}^{\prime}$. At the anodic limit, the current rises from $0.14 \mathrm{~A} \mathrm{~cm}^{-2}$ without the presence of steam

349 at point $\mathrm{A} 1$ to $0.465 \mathrm{~A} \mathrm{~cm}^{-2}$ with the presence of steam at point $\mathrm{A}^{\prime}$, these results are in agreement

350 with the literature [39].

352 In order to understand the effect of the steam's presence on increasing the current density of the 353 evolution of hydrogen gas reaction, the potential voltammetry scan is limited between -0.8 and -

$3540.3 \mathrm{~V}$ respectively as shown in Fig. 5(d). It is very clear from constraining the scan range that 355 there is a considerable effect of the presence of steam in increasing the current density of the 356 evolution of hydrogen gas reaction. It increases from $-0.164 \mathrm{Acm}^{-2}$ at $\mathrm{C} 1$ to $-0.51 \mathrm{Acm}^{-2}$ at $\mathrm{C} 1$ '. 357 This result is shown in Fig. 5(d) through the increase of the molybdenum metal activity with steam 358 and makes a significant change on the $\mathrm{H}_{2}$ evolution.

\section{$360 \quad 3.1 .5 \quad$ St.st working electrode}

361 Stainless steel (302) is composed of iron, nickel, chromium, manganese, silicon, carbon, 362 phosphorus and sulphur. It was used in this study as a working electrode to examine its stability 363 and productivity in the molten salts. Fig. 6(a) shows a cyclic voltammetry scan at an operating 364 temperature of $300{ }^{\circ} \mathrm{C}$ and a scan rate of $100 \mathrm{mV} \mathrm{s}^{-1}$. At the anodic limit $\mathrm{A} 1$, the corresponding 365 peak is due to the oxidation of the melt $\left(2 \mathrm{OH}^{-} \rightarrow 0.5 \mathrm{O}_{2}(\mathrm{~g})+\mathrm{H}_{2} \mathrm{O}+2 \mathrm{e}^{-}\right)$while the reduction of 366 the water formed at the anodic limit is seen at the cathodic limit $\mathrm{C} 1$. The corresponding reaction 367 of the reduction of water becomes is shown in reaction (6).

369 In the case of the oxidation peak A2, it corresponds to the oxidation occurring on the surface of 370 the stainless steel working electrode and the potential of oxidation observed at $-0.33 \mathrm{~V}$. 
371 Subsequently, the CV scan is limited to a range between $-0.8 \mathrm{~V}$ and $-0.3 \mathrm{~V}$ in order to focus the

372 scan on the cathodic limit for the HER as shown in Fig. 6(b). No change in the reduction potential

373 which starts at $-0.5 \mathrm{~V}$, and the current at the cathodic limit $\mathrm{C} 1$ which approximately equals $-1.4 \mathrm{~A}$

$374 \mathrm{~cm}^{-2}$; is discernible. The oxidation peak A2 disappears when the CV scan is limited, even though

375 the potential of the return scan is positive prior to A2 peak.

377 Fig. 6(c) and d show the cyclic voltammetry of the stainless steel with and without the presence 378 of steam with molten salts and same working conditions of temperature at $300{ }^{\circ} \mathrm{C}$ and scan rate of $379100 \mathrm{mV} \mathrm{s}^{-1}$. No significant change can be observed from the figure regarding the presence of steam 380 with hydroxide salts at the cathodic limit $\mathrm{C} 1$ for the evolution of hydrogen reaction as shown in 381 Fig. 6(c). At the oxidation peak, the current density increased from $0.12 \mathrm{~A} \mathrm{~cm}^{-2}$ without the 382 presence of steam (A2') to $0.23 \mathrm{~A} \mathrm{~cm}^{-2}$ with the presence of steam (A2). This increase in the 383 current density from A2' to A2 is responsible for increasing the surface area of the oxide metal.

385 The effect of changing the operating temperature of the eutectic molten hydroxide on the working 386 electrode kinetics activity is shown in Fig. S1 was also studied. The studied temperatures were 225 387 and $300{ }^{\circ} \mathrm{C}$ respectively. It can be observed that the evolution of hydrogen gas becomes more 388 efficient and sees an increase with increasing temperature for all working electrodes.

\subsection{Working electrode's performance evaluation}

391 The stability of the reference electrode in different working conditions and its working comparion 392 against other reference electrode has already been verified in previous studies [30, 40]. The 393 stability, reusability and reproducibility of the $\mathrm{Ni} / \mathrm{Ni}(\mathrm{OH})_{2}$ reference electrode have also been 394 reported with good experimentation. This electrode has worked with stability and reproducibility 
396 ones ( quasi Pt and Ag) has also been made.

398 After studying the kinetic reaction of each working electrode separately in the eutectic molten 399 hydroxide at different operating conditions respectively; it is imperative to compare their 400 performance. This is essential for discerning which electrode provides more affordable, durable, 401 stable kinetics; and also fast catalytic response for the HER. The comparison focuses mainly on 402 the cathodic limit of the HER. Cyclic voltammetry scans of the different working electrodes (i.e. $403 \mathrm{Ni}, \mathrm{Pt}, \mathrm{Ag}, \mathrm{Mo}, \mathrm{St} . \mathrm{st}$ ) are compared in the eutectic molten hydroxide at a temperature of $300{ }^{\circ} \mathrm{C}$, a 404 potential scan rate of $100 \mathrm{mVs}^{-1}$ and an argon gas atmosphere as shown in Fig. 7.

406 It is obvious from Fig. 7 that each working electrode has a unique reduction potential value. It 407 can, therefore, be observed from the above figure that the platinum working electrode had more 408 positive reduction potential value (approximately $-0.47 \mathrm{~V}$ ) followed by the reduction potential of 409 the nickel working electrode (approximately $-0.49 \mathrm{~s} \mathrm{~V}$ ) and then the reduction potential of the 410 stainless steel working electrode at $-0.51 \mathrm{~V}$. The reduction potential values of the silver and 411 molybdenum working electrodes occurred at the lower end of the comparison at $-0.53 \mathrm{~V}$ and -0.56 412 V respectively.

414 The results of this study are in close comparison with the literature [41] in which $\mathrm{Ag} / \mathrm{AgCl}$ was 415 used as a reference electrode. In this study, current density at the cathodic limit is the highest for 416 nickel working electrode followed by the stainless steel and platinum working electrodes 417 respectively. However, silver and molybdenum have the lowest current density respectively. Table 
4182 , displays the reduction potential and the current density at the cathodic limit as observed from

419 the above figure for different working electrodes.

421 A high current density measured at the cathodic limit means a high HER. This HER is influenced

422 directly by the electrocatalytic activity of the working electrode inside the eutectic molten

423 hydroxide. As mentioned and tabulated in Table 2. The highest hydrogen evolution reaction that 424 can be achieved at the cathodic limit is done by using the nickel working electrode followed by 425 stainless steel, platinum, silver and finally molybdenum. Therefore, the nickel wire had a higher 426 electrode activity in comparison to the other working electrodes. This behaviour reinforces nickel 427 as a popular choice in electrochemical processes as cathode material for the hydrogen gas evolution 428 reaction. However, some studies such as [42] have revealed that nickel can be deactivated during $429 \mathrm{H}_{2}$ generation in alkaline water electrolysis and the metal requires the $\mathrm{V}_{2} \mathrm{O}_{5}$ addition to the 430 electrolyte to cause reactivation. These observed results were repeated for three times for all 431 working electrodes, no change on the observed results was experienced.

\section{$433 \quad 3.3$ Hydrogen evolution reaction (HER)}

434 Fig. 8(a) shows the obtained current-time chronoamperometry at a constant potential of all tested 435 working electrodes in the eutectic molten hydroxide during 10 minutes of the HER. This test was 436 executed at an operating temperature of $300{ }^{\circ} \mathrm{C}$ and $40 \mathrm{~cm}^{3} \mathrm{~min}^{-1}$ argon atmosphere. The 437 chronoamperograms show that the electrodes change during the first stages of HER, accomplishing 438 a near stationary state. Their reactivity is retained along the noted time period, with platinum 439 followed by nickel being by far, the best one material among the tried (tested) materials and 440 displaying the highest current density values in comparison to stainless steel, silver and 
441 molybdenum. This result confirms that the blank metal of platinum and nickel working electrodes

442 in the eutectic molten hydroxide respectively have a better performance for splitting steam to

443 produce hydrogen gas. The stainless steel working electrode is third in order for hydrogen gas

444 production.

446 The performance of the different working electrodes was also tested with the presence of steam

447 inside the eutectic molten hydroxide and at an operating temperature of $300^{\circ} \mathrm{C}$, as shown in Fig.

448 8(b). It is obvious from the figure that the attained current density value of different working

449 electrodes (without steam) slightly increased with the presence of steam inside the eutectic molten

450 hydroxide. It can also be observed from the above figure that a significant increase in the current

451 density of stainless steel as the working electrode, occurs in the presence of steam. This increase

452 indicates that the electro-catalytic activity of stainless steel under these condition mirrors the value

453 of nickel metal.

455 On the other hand, platinum still ranks as the most electro-active for the hydrogen evolution 456 reaction. Despite this, its use was generally limited in history because it is classified as a precious 457 metal in comparison to the others. Similar to steam introduction to increase HER strategy, doping 458 strategy of nanosheets and other conducting materials with heteroatom to increase the 459 electrocatalytic activity and resultantly increase HER, was also applied in literature [43-45] with 460 a positive outcome. In addition to nanosheets, nanocrystals of trimetallic alloy [46] were also used 461 for HER with high catalytic power. In this study and in other mentioned ones the main focus is the 462 electrocatalytic activity of the materials/ or electrodes which directly plays a key role in HER. 


\section{Conclusions}

465 The aims behind this detailed research were to find cheaper, electrocatalytic working electrodes,

466 vs a novel $\mathrm{Ni} / \mathrm{Ni}(\mathrm{OH})_{2}$ reference electrode, that can be used to increase the feasibility of hydrogen

467 gas production in eutectic molten hydroxide $(\mathrm{NaOH}-\mathrm{KOH}, 49-51 \mathrm{~mol} \%)$, at $300{ }^{\circ} \mathrm{C}$ temperature.

468 The most important findings that can be drawn from the results are:

469 - The reduction potential of the hydrogen evolution reaction using different working 470 electrodes was in the order of (more positive to negative reduction potential): $\mathrm{Pt}>\mathrm{Ni}>$ 471 St.st $>$ Ag $>$ Mo. The performance of each working electrode for the hydrogen evolution 472 reaction was confirmed through chronoamperometry tests at a constant potential of $-0.7 \mathrm{~V}$. 473 These tests confirm the stability and productivity of each working electrode. The produced 474 chronoamperograms found that the platinum had the highest current density followed by 475 nickel, stainless steel, silver and then molybdenum at the constant potential of $-0.7 \mathrm{~V}$.

476 - It was also found from the cyclic voltammograms that the presence of steam inside the 477 eutectic molten hydroxide is apparent in increasing the current density at the cathodic limit 478 for the hydrogen evolution reaction. However, the starting point of reduction potential for 479 the hydrogen evolution reaction was still approximately the same with and without the 480 presence of steam inside the eutectic molten hydroxide.

481 - The effect of increasing the operating temperature of the eutectic molten hydroxide 482 influenced the performed cyclic voltammetry scans. This effect appeared to clearly shift the reduction potential in a positive direction at high temperatures. This positive shift was applicable for all tested working electrodes. The shift in the reduction potential with an increase in the operating temperature was approximately $0.1 \mathrm{~V}$ for all tested working 

the hydrogen evolution reaction.

\section{Acknowledgement}

489 The authors are grateful for the financial supports from the EPSRC (EP/J000582/1 and

490 EP/F026412/1), and Ningbo Municipal People's Governments (3315 Plan and 2014A35001-1). 


\section{References}

492 1. Yang, J., et al., Achieving excellent dielectric performance in polymer composites with 493 ultralow filler loadings via constructing hollow-structured filler frameworks. Composites

2. Yadav, A. and N. Verma, Efficient hydrogen production using Ni-graphene oxidePart A: Applied Science and Manufacturing, 2020. 131: p. 105814.

dispersed laser-engraved 3D carbon micropillars as electrodes for microbial electrolytic cell. Renewable energy, 2019. 138: p. 628-638.

3. Ganci, F., et al., Nanostructured electrodes for hydrogen production in alkaline electrolyzer. Renewable Energy, 2018. 123: p. 117-124.

4. Hassan, M.H.A., et al., Kinetic and thermodynamic evaluation of effective combined promoters for $\mathrm{CO} 2$ hydrate formation. Journal of Natural Gas Science and Engineering, 2020: p. 103313.

5. Licht, S., et al., Comparison of Alternative Molten Electrolytes for Water Splitting to Generate Hydrogen Fuel. Journal of The Electrochemical Society, 2016. 163(10): p. F1162-F1168.

6. Sun, L., et al., Ultrahigh discharge efficiency and improved energy density in rationally designed bilayer polyetherimide-BaTiO 3/P (VDF-HFP) composites. Journal of Materials Chemistry A, 2020. 8(11): p. 5750-5757.

7. Sakamura, Y., Zirconium behavior in molten LiCl-KCl eutectic. Journal of the electrochemical society, 2004. 151(3): p. C187-C193.

8. Gao, P., et al., A quartz sealed $\mathrm{Ag} / \mathrm{AgCl}$ reference electrode for $\mathrm{CaCl} 2$ based molten salts. Journal of Electroanalytical Chemistry, 2005. 579(2): p. 321-328.

9. Wang, H., et al., A robust alumina membrane reference electrode for high temperature molten salts. Journal of The Electrochemical Society, 2012. 159(9): p. H740-H746.

10. Papaderakis, A., et al., Hydrogen evolution at Ir-Ni bimetallic deposits prepared by galvanic replacement. Journal of Electroanalytical Chemistry, 2018. 808: p. 21-27.

11. Abbasi, S., et al., Application of the statistical analysis methodology for photodegradation of methyl orange using a new nanocomposite containing modified $\mathrm{TiO} 2$ semiconductor with SnO2. International Journal of Environmental Analytical Chemistry, 2019: p. 1-17.

12. Rashid, T., et al., Formulation of Zeolite-supported Nano-metallic Catalyst and its Application in Textile Effluent Treatment. Journal of Environmental Chemical Engineering, 2020: p. 104023.

13. Miles, M.H., Exploration of Molten Hydroxide Electrochemistry for Thermal Battery Applications. Journal of Applied Electrochemistry, 2003. 33(11): p. 1011-1016.

14. Kadier, A., et al., Hydrogen gas production with an electroformed Ni mesh cathode catalysts in a single-chamber microbial electrolysis cell (MEC). International Journal of Hydrogen Energy, 2015. 40(41): p. 14095-14103.

15. Ge, J., et al., Metallic Nickel Preparation by Electro-Deoxidation in Molten Sodium Hydroxide. Journal of The Electrochemical Society, 2015. 162(9): p. E185-E189.

16. Kacprzak, A., Hydroxide electrolyte direct carbon fuel cells-Technology review. International Journal of Energy Research, 2019. 43(1): p. 65-85.

17. Yavuz, A., et al., Nickel-based materials electrodeposited from a deep eutectic solvent on steel for energy storage devices. Applied Physics A, 2019. 125(8): p. 494. 
18. Ji, D., et al., The optimization of electrolyte composition for $\mathrm{CH} 4$ and $\mathrm{H} 2$ generation via $\mathrm{CO} 2 / \mathrm{H} 2 \mathrm{O}$ co-electrolysis in eutectic molten salts. International Journal of Hydrogen Energy, 2019. 44(11): p. 5082-5089.

19. Zabinski, P., et al., Electrodeposited Co-Mo-C cathodes for hydrogen evolution in a hot concentrated $\mathrm{NaOH}$ solution. Journal of The Electrochemical Society, 2003. 150(10): p. C717-C722.

20. Jayalakshmi, M., et al., Electrochemical Characterization of Ni-Mo-Fe Composite Film in Alkali Solution. International Journal of Electrochemical Science 2008. 3(8): p. 908-917.

21. Döner, A., İ. Karc1, and G. Kardaş, Effect of C-felt supported Ni, Co and NiCo catalysts to produce hydrogen. International Journal of Hydrogen Energy, 2012. 37(12): p. 9470-9476.

22. Al-Shara, N.K., et al., Electrochemical investigation of novel reference electrode Ni/Ni $(\mathrm{OH})_{2}$ in comparison with silver and platinum inert quasi-reference electrodes for electrolysis in eutectic molten hydroxide. international journal of hydrogen energy, 2019. 44(50): p. 27224-27236.

23. Zhou, W.-D., et al., Discriminable Sensing Response Behavior to Homogeneous Gases Based on n-ZnO/p-NiO Composites. Nanomaterials, 2020. 10(4): p. 785.

24. Gayer, K.H. and A. Garrett, The equilibria of nickel hydroxide, Ni $(\mathrm{OH}) 2$, in solutions of hydrochloric acid and sodium hydroxide at 25. Journal of the American Chemical Society, 1949. 71(9): p. 2973-2975.

25. Hojamberdiev, M., et al., Synergistic effect of g-C3N4, Ni (OH) 2 and halloysite in nanocomposite photocatalyst on efficient photocatalytic hydrogen generation. Renewable energy, 2019. 138: p. 434-444.

26. Siwek, K., et al., 3D nickel foams with controlled morphologies for hydrogen evolution reaction in highly alkaline media. International Journal of Hydrogen Energy, 2019. 44(3): p. 1701-1709.

27. Dastan, D. and A. Banpurkar, Solution processable sol-gel derived titania gate dielectric for organic field effect transistors. Journal of Materials Science: Materials in Electronics, 2017. 28(4): p. 3851-3859.

28. Dastan, D., et al., Morphological and electrical studies of titania powder and films grown by aqueous solution method. Advanced Science Letters, 2016. 22(4): p. 950-953.

29. Shan, K., et al., Conductivity and Mixed Conductivity of a Novel Dense Diffusion Barrier and Sensing Properties of Limiting Current Oxygen Sensors. Dalton Transactions, 2020.

30. Al-Shara, N.K., et al., Electrochemical investigation of novel reference electrode Ni/Ni $(\mathrm{OH})_{2}$ in comparison with silver and platinum inert quasi-reference electrodes for electrolysis in eutectic molten hydroxide. International Journal of Hydrogen Energy, 2019.

31. Zuo, H., et al., Bilayer carbon nanowires/nickel cobalt hydroxides nanostructures for highperformance supercapacitors. Materials Letters, 2020. 263: p. 127217.

32. Cox, A. and D.J. Fray, Mechanistic investigation into the electrolytic formation of iron from iron (III) oxide in molten sodium hydroxide. Journal of Applied Electrochemistry, 2008. 38(10): p. 1401-1407.

33. Zhu, X., et al., Fabrication of core-shell structured Ni@ BaTiO3 scaffolds for polymer composites with ultrahigh dielectric constant and low loss. Composites Part A: Applied Science and Manufacturing, 2019. 125: p. 105521.

34. Híveš, J., et al., Electrochemical Formation of Ferrate (VI) in a Molten $\mathrm{NaOH}-\mathrm{KOH}$ System. Electrochemistry communications, 2006. 8(11): p. 1737-1740. 
35. Al-Shara, N.K., et al., Design and optimization of electrochemical cell potential for

36. Couper, A.M., D. Pletcher, and F.C. Walsh, Electrode materials for electrosynthesis. Chemical Reviews, 1990. 90(5): p. 837-865.

37. Diez-Gonzalez, S. and S.P. Nolan, Copper, silver, and gold complexes in hydrosilylation reactions. Accounts of chemical research, 2008. 41(2): p. 349-358.

38. Pierson, J., D. Wiederkehr, and A. Billard, Reactive magnetron sputtering of copper, silver, and gold. Thin Solid Films, 2005. 478(1-2): p. 196-205.

39. Narendranath, J., et al., Electrochemical recovery of hydrogen and elemental sulfur from hydrogen sulfide gas by two-cell system. Energy Sources, Part A: Recovery, Utilization, and Environmental Effects, 2019: p. 1-14.

40. Al-Shara, N.K., et al., Electrochemical study of different membrane materials for the fabrication of stable, reproducible and reusable reference electrode. Journal of Energy Chemistry, 2020.

41. Chaurasia, A.K., H. Goyal, and P. Mondal, Hydrogen gas production with Ni, Ni-Co and $\mathrm{Ni}-\mathrm{Co}-\mathrm{P}$ electrodeposits as potential cathode catalyst by microbial electrolysis cells. International Journal of Hydrogen Energy, 2019.

42. Abouatallah, R., D. Kirk, and J. Graydon, Impedance study of nickel cathode reactivation by vanadium during hydrogen evolution in alkaline water. Electrochemical and solid-state letters, 2002. 5(3): p. E9-E12.

43. Geng, S., et al., Engineering defects and adjusting electronic structure on $\mathrm{S}$ doped $\mathrm{MoO} 2$ nanosheets toward highly active hydrogen evolution reaction. Nano Research, 2020. 13(1): p. 121-126.

44. Geng, S., W. Yang, and Y.S. Yu, Building MoS2/S-doped g-C3N4 layered heterojunction electrocatalysts for efficient hydrogen evolution reaction. Journal of catalysis, 2019. 375: p. 441-447.

45. Geng, S., et al., Activating the MoS2 Basal Plane by Controllable Fabrication of Pores for an Enhanced Hydrogen Evolution Reaction. Chemistry-A European Journal, 2018. 24(71): p. $19075-19080$.

46. $\mathrm{Li}, \mathrm{M}$., et al., Modulating the surface segregation of $\mathrm{PdCuRu}$ nanocrystals for enhanced all-pH hydrogen evolution electrocatalysis. Journal of Materials Chemistry A, 2019. 7(35): p. 20151-20157. 


\section{List of Tables}

613

Table 1. Working electrode's surface area specifications.

\begin{tabular}{lcc}
\hline Working electrode & $\begin{array}{c}\text { Diameter } \\
(\mathbf{c m})\end{array}$ & $\begin{array}{c}\text { Surface area } \\
\left(\mathbf{c m}^{\mathbf{2}}\right)\end{array}$ \\
\hline Nickel & 0.05 & 0.22 \\
Platinum & 0.05 & 0.22 \\
Silver & 0.10 & 0.44 \\
Molybdenum & 0.10 & 0.44 \\
Stainless steel & 0.025 & 0.11 \\
\hline
\end{tabular}

614

615 
616

617

Table 2. Reduction potential and the current limit at cathodic limit.

618

\begin{tabular}{cccc}
\hline $\begin{array}{c}\text { Working } \\
\text { electrode }\end{array}$ & $\begin{array}{c}\text { Temperature } \\
\left({ }^{\circ} \mathbf{C}\right)\end{array}$ & $\begin{array}{c}\text { Reduction potential } \\
\mathbf{E r e d}(\mathbf{V})\end{array}$ & $\begin{array}{c}\text { Current density } \\
\mathbf{j}\left(\mathbf{A ~ c m}^{-2}\right)\end{array}$ \\
\hline $\mathrm{Ni}$ & 300 & -0.49 & -1.67 \\
$\mathrm{Pt}$ & 300 & -0.47 & -1.23 \\
$\mathrm{Ag}$ & 300 & -0.53 & -0.20 \\
$\mathrm{Mo}$ & 300 & -0.55 & -0.16 \\
$\mathrm{St.st}$ & 300 & -0.51 & -1.41 \\
\hline
\end{tabular}




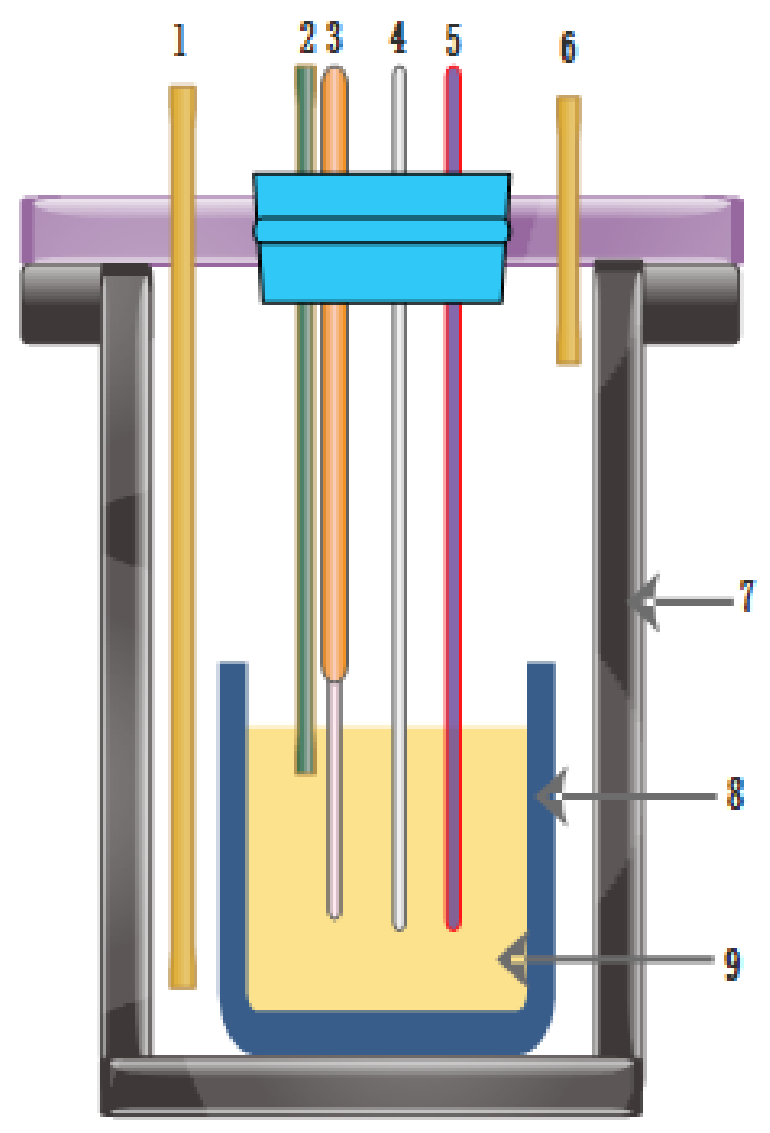

625 Fig. 1. Experimental setup: (1) Argon inlet, (2) Steam inlet, (3) Reference electrode, (4) Working electrode, 626 (5) Counter electrode, (6) Argon outlet, (7), Reaction vessel, (8) Corundum crucible and (9) Molten salt. 

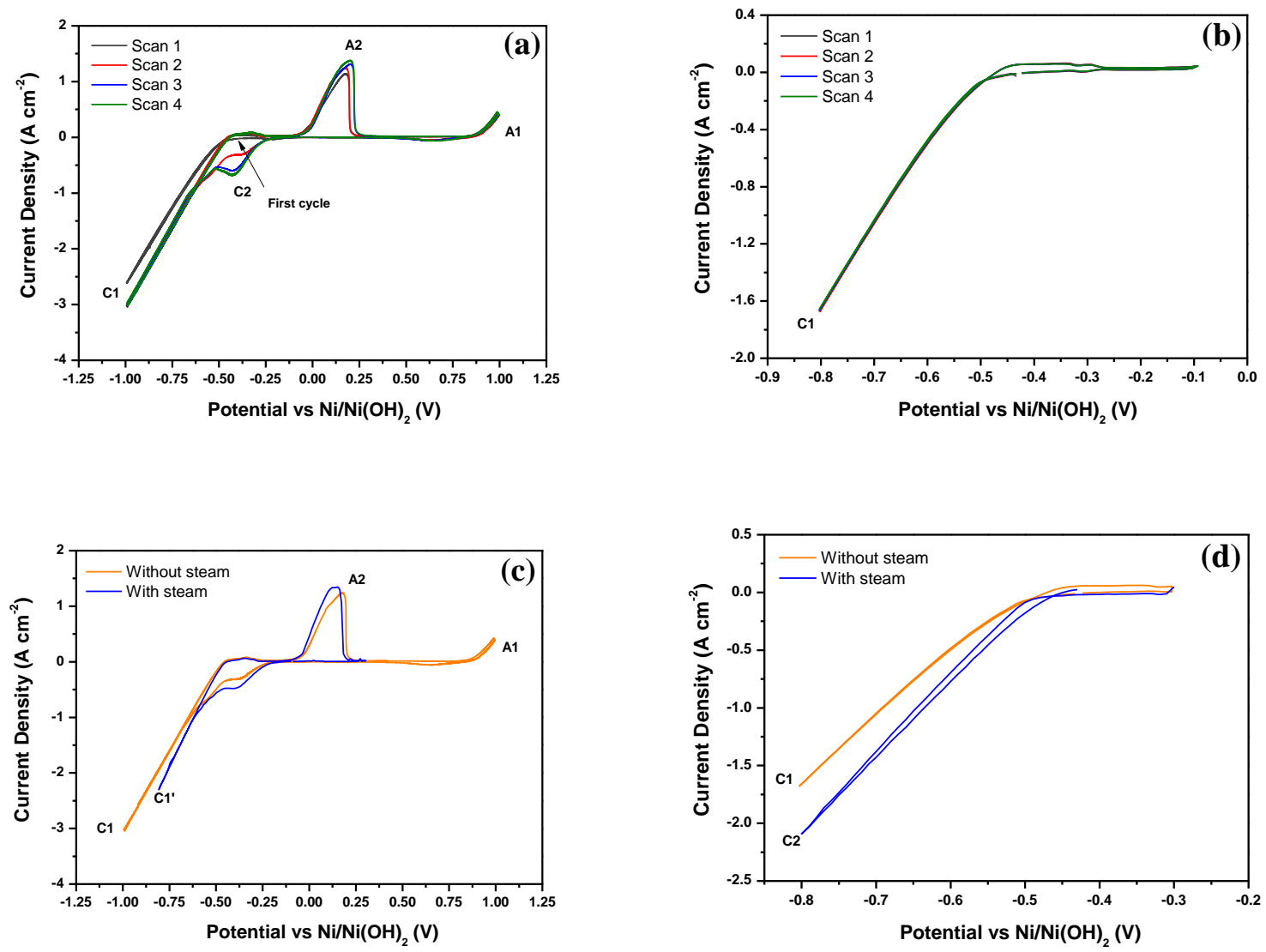

630 Fig. 2. Voltammetric peaks of a $0.5 \mathrm{~mm}$ nickel working electrode in the eutectic molten hydroxide at a 631 temperature of $300^{\circ} \mathrm{C}$. RE: Ni/Ni(OH)2; CE: $5 \mathrm{~mm}$ stainless steel rod; atmosphere of $\mathrm{Ar}$ gas at $40 \mathrm{~cm}^{3} \mathrm{~min}^{-}$ $632{ }^{1}$; the immersion depth : $14 \mathrm{~mm}$; scan rate: $100 \mathrm{mVs}^{-1}$, (a) Scan negatively between -1.0 and $1.0 \mathrm{~V}$, (b) 633 Limiting the scan between -0.8 and $-0.1 \mathrm{~V}$, (c) Scan negatively between -0.8 and $1.0 \mathrm{~V}$ for steam analysis, 634 (d) Limiting the scan between -0.8 and $-0.3 \mathrm{~V}$ for steam analysis. 

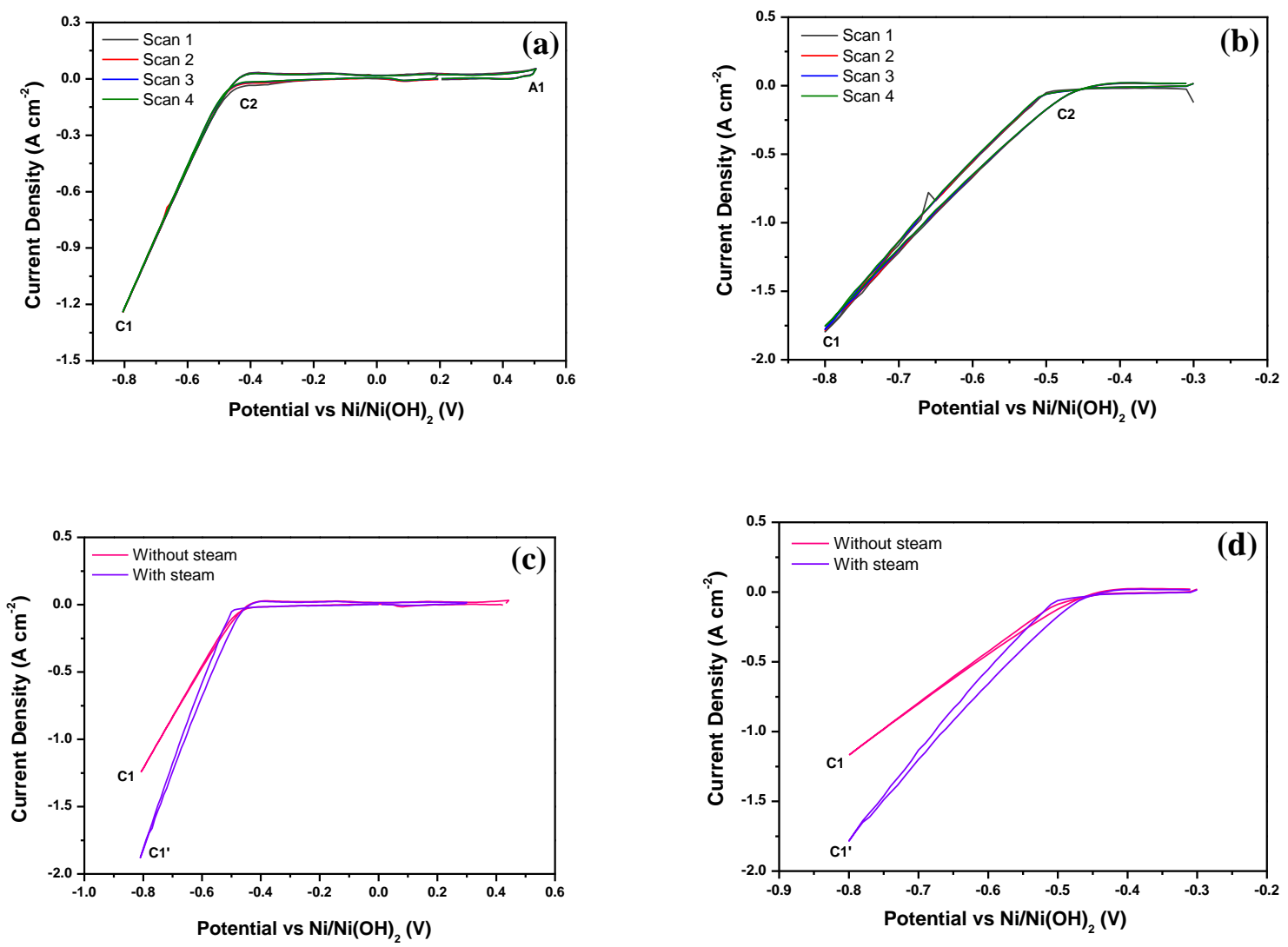

638 Fig. 3. Voltammetric peaks of a $0.5 \mathrm{~mm}$ Platinum working electrode in the eutectic molten hydroxide at a temperature of $300{ }^{\circ} \mathrm{C}$. RE: $\mathrm{Ni} / \mathrm{Ni}(\mathrm{OH})_{2}$; CE: $5 \mathrm{~mm} \mathrm{St.st}$ rod; an $\mathrm{Ar}$ gas atmosphere at $40 \mathrm{~cm}^{3} \mathrm{~min}^{-1}$; the immersion depth: $14 \mathrm{~mm}$; Scan rate: $100 \mathrm{mV} \mathrm{s}^{-1}$, (a) Scan negatively between -0.8 and $0.5 \mathrm{~V}$, (b) ) Limiting the scan between -0.8 and $-0.3 \mathrm{~V}$, (c) Scan negatively between -0.8 and $0.5 \mathrm{~V}$ for steam analysis, (d) Limiting the scan between -0.8 and $-0.3 \mathrm{~V}$ for steam analysis. 

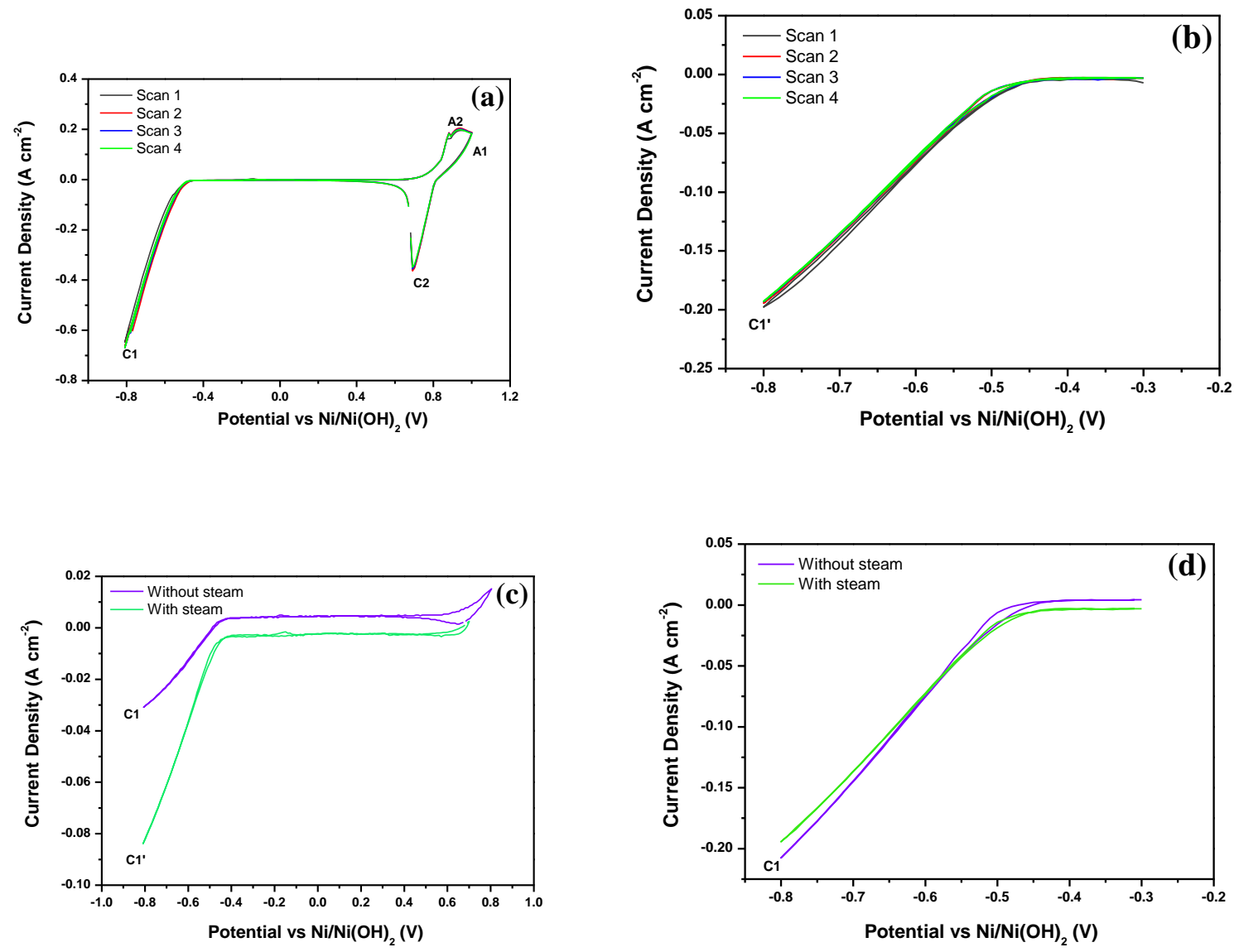

646 Fig. 4. Voltammetric peaks of a $1.0 \mathrm{~mm}$ silver working electrode in the eutectic molten hydroxide at scan 647 rate of $100 \mathrm{mVs}^{-1}$ and operating temperature of $300{ }^{\circ} \mathrm{C}$. $\mathrm{RE}$ : $\mathrm{Ni} / \mathrm{Ni}(\mathrm{OH})_{2}$; CE: $5 \mathrm{~mm} \mathrm{St.st}$ rod; an Ar gas 649 Limiting the scan between -0.8 and $-0.3 \mathrm{~V}$, (c) Scan negatively from -0.8 to $1.0 \mathrm{~V}$ for steam analysis, (d) 650 Steam analysis by limiting the scan between -0.8 and $-0.3 \mathrm{~V}$. 

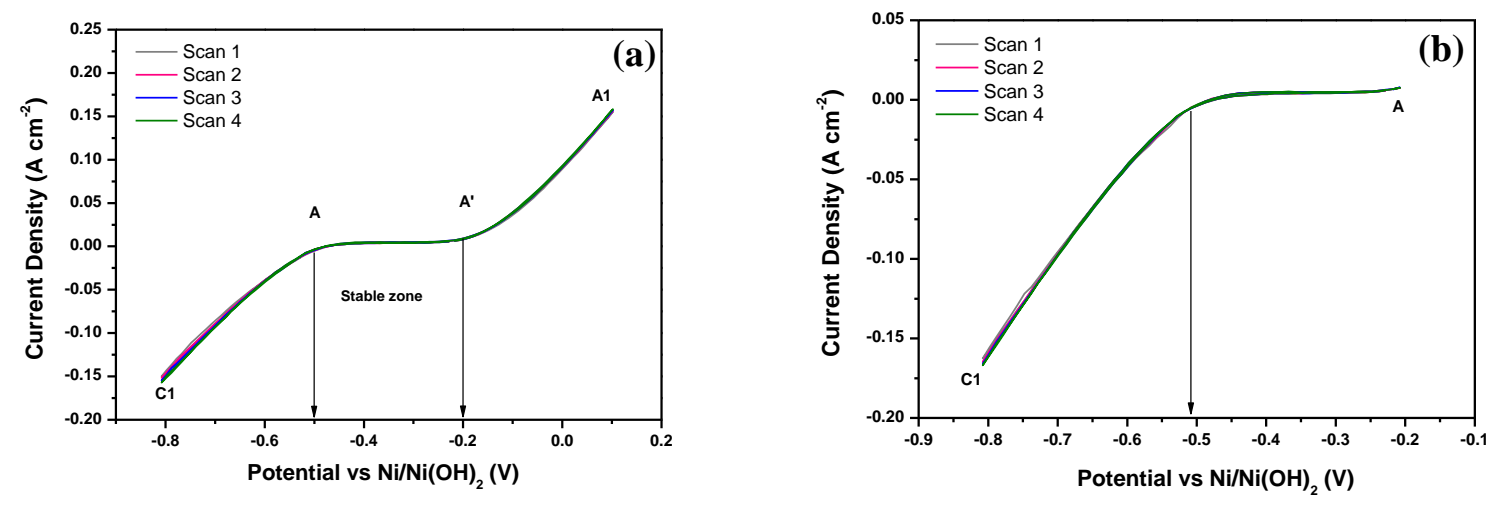

652
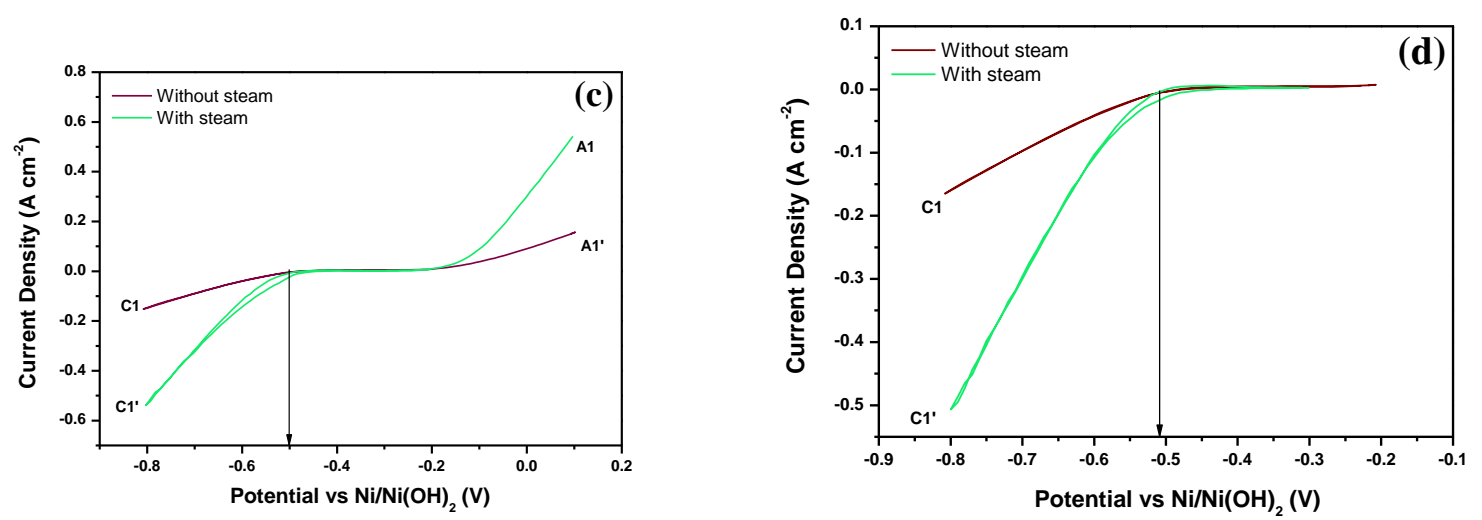

654 Fig. 5. Voltammetric peaks of a $1.0 \mathrm{~mm}$ molybdenum working electrode in the eutectic molten hydroxide 655 at a temperature of $300{ }^{\circ} \mathrm{C}$ and a scan rate of $100 \mathrm{mV} \mathrm{s}^{-1}$. RE: $\mathrm{Ni} / \mathrm{Ni}(\mathrm{OH})_{2}$; CE: $5 \mathrm{~mm} \mathrm{St.st} \mathrm{rod;} \mathrm{an} \mathrm{Ar} \mathrm{gas}$ 656 atmosphere at $40 \mathrm{~cm}^{3} \mathrm{~min}^{-1}$; the immersion depth: $14 \mathrm{~mm}$; (a) Scan negatively from -0.8 to $0.1 \mathrm{~V}$, (b) 657 Limiting the scan between -0.8 and $-0.2 \mathrm{~V}$, (c) Scan negatively from -0.8 to $0.1 \mathrm{~V}$ for steam analysis, (d) 658 Limiting the scan between -0.8 and $-0.3 \mathrm{~V}$ for steam analysis. 

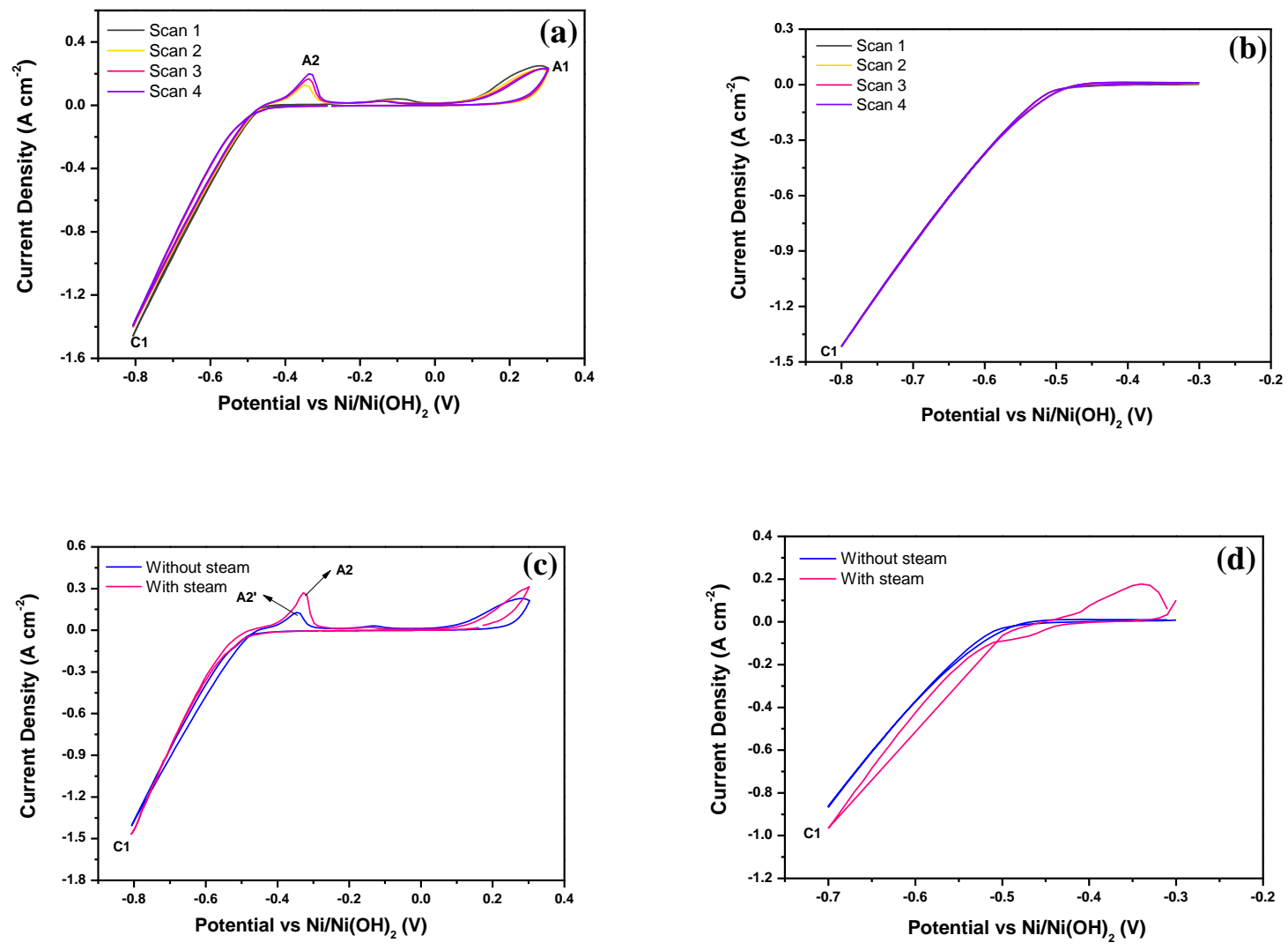

Fig. 6. Voltammetric peaks of a $0.25 \mathrm{~mm}$ stainless steel working electrode in the eutectic molten hydroxide 663 at a temperature of $300{ }^{\circ} \mathrm{C}$. RE: $\mathrm{Ni} / \mathrm{Ni}(\mathrm{OH})_{2}$; CE: $5 \mathrm{~mm} \mathrm{St.st} \mathrm{rod;} \mathrm{an} \mathrm{atmosphere} \mathrm{of} \mathrm{Ar}$ at $40 \mathrm{~cm}^{3} \mathrm{~min}^{-1}$; the 664 immersion depth: $14 \mathrm{~mm}$; Scan rate: $100 \mathrm{mV} \mathrm{s}^{-1}$, (a) Scan negatively from -0.8 to $0.3 \mathrm{~V}$, (b) Limiting the 665 scan between -0.8 and $-0.3 \mathrm{~V}$ (c) Scan negatively from -0.8 to $0.3 \mathrm{~V}$ for steam analysis, (d) Steam analysis 666 by limiting the scan between -0.8 and $-0.3 \mathrm{~V}$. 


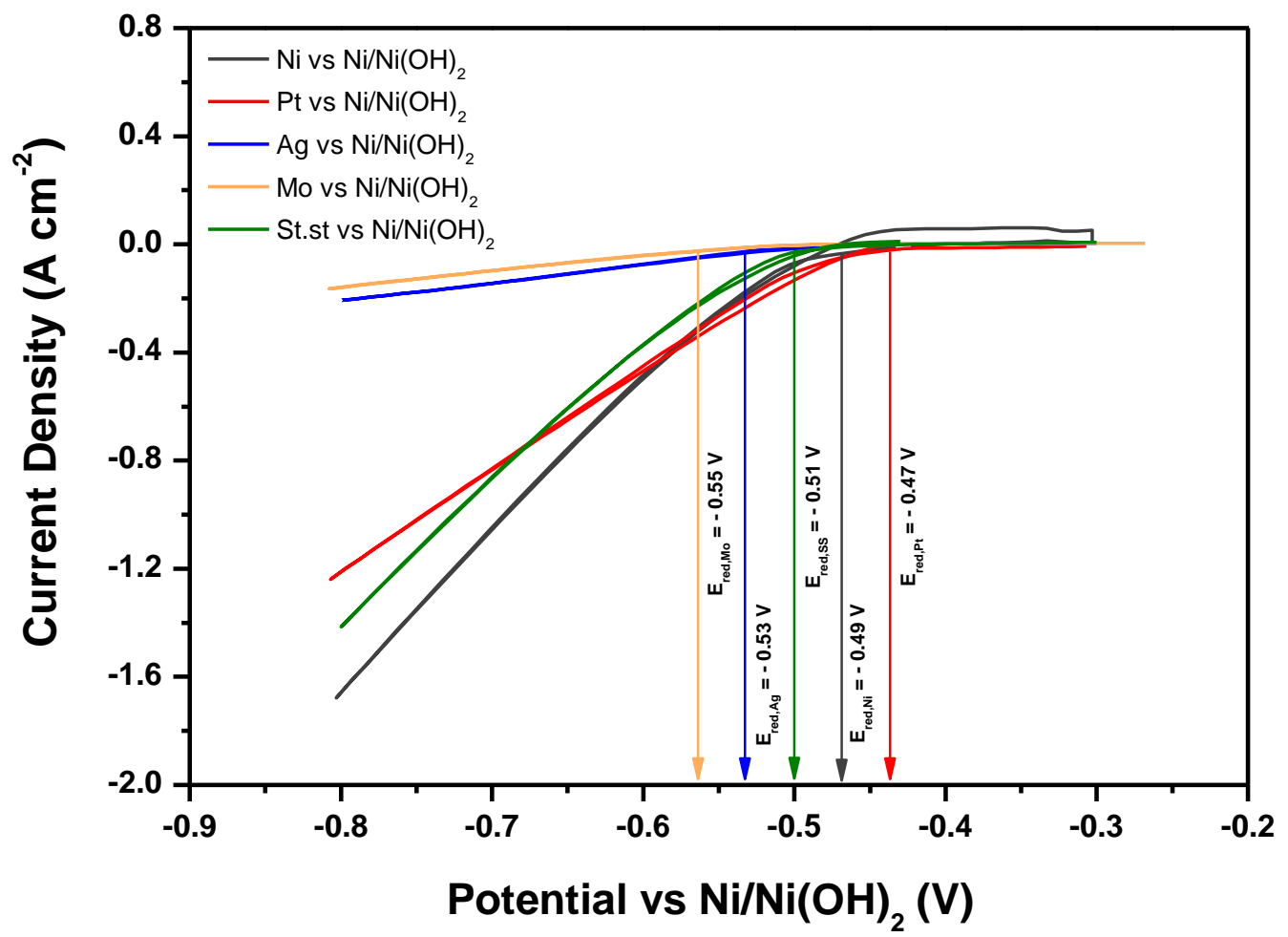

673 Fig. 7. Comparison of cyclic voltammograms of $\mathrm{Ni}, \mathrm{Pt}, \mathrm{Ag}$, Mo, St.st working electrode in the eutectic molten hydroxide at a temperature of $300{ }^{\circ} \mathrm{C}$ and scan rate of $100 \mathrm{mV} \mathrm{s}^{-1}$. RE: $0.5 \mathrm{~mm}$ of Ni/Ni(OH$)_{2}$ and CE: $5 \mathrm{~mm}$ of St.st; immersion depth: $14 \mathrm{~mm}$, an Ar gas atmosphere: $40 \mathrm{~cm}^{3} \mathrm{~min}^{-1}$. 

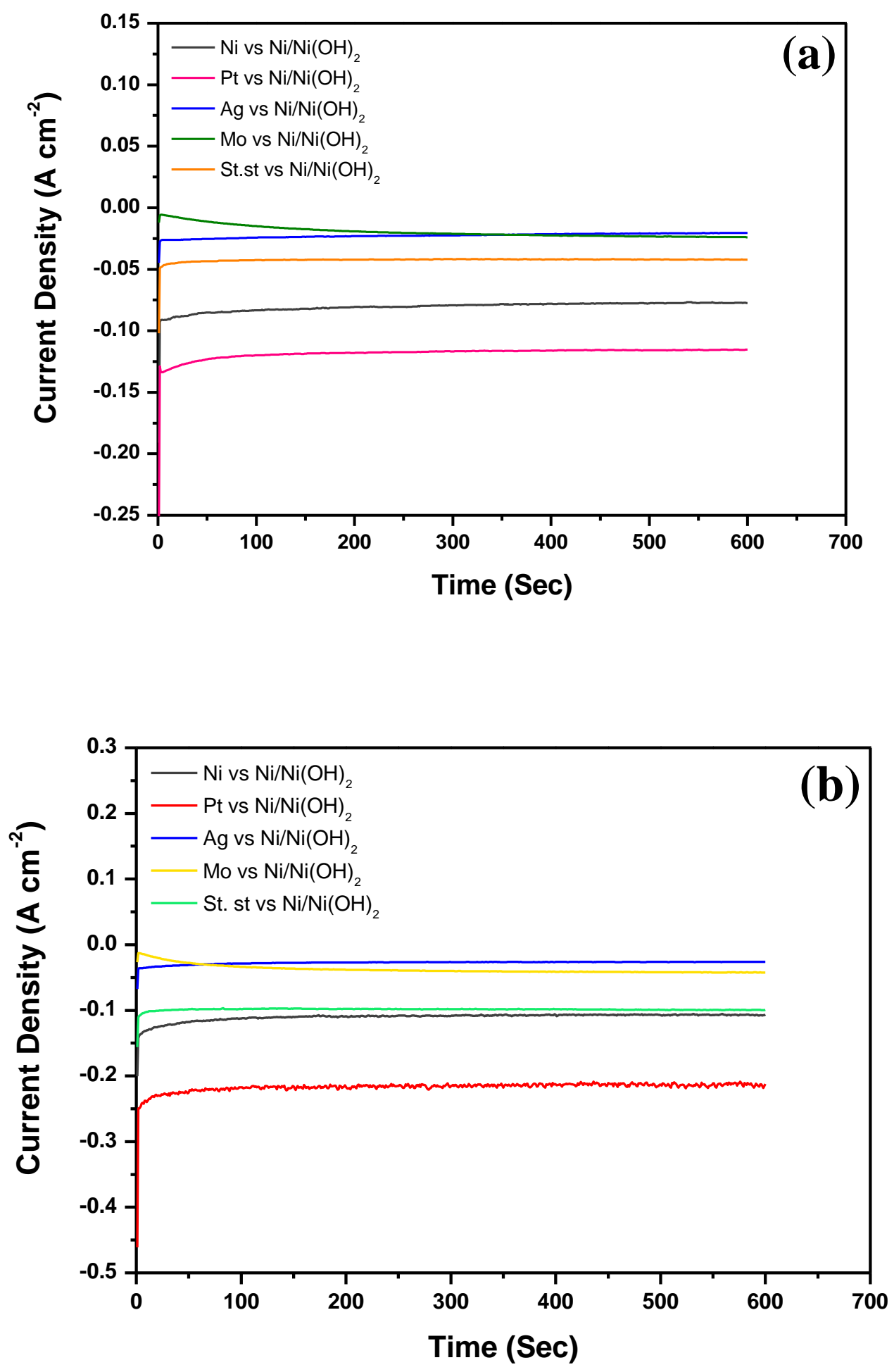

679 Fig. 8. Chronoamperograms of the hydrogen evolution reaction for all working electrodes (Ni, Pt, Ag, Mo, 680 St.st) in the eutectic molten hydroxide at a temperature of $300{ }^{\circ} \mathrm{C}$, and at an applied potential of $-0.7 \mathrm{~V}$ 
681 during $10 \mathrm{~min}$; (a) Without steam and argon gas atmosphere at $40 \mathrm{~cm}^{3} \mathrm{~min}^{-1}$, (b) With steam and argon gas 682 atmosphere at $40 \mathrm{~cm}^{3} \mathrm{~min}^{-1}$. 